\title{
Elemental and mineralogical compositions of sediments in the Atacama Trench
}

\author{
Min LuO ${ }^{1}$, Yilun CHEN ${ }^{1}$, DuOfu CHEN ${ }^{1}$, FRANK
} WENZHÖFER ${ }^{2}$, RONNIE N. GLUD ${ }^{3}$

${ }^{1}$ HAST, College of Marine Sciences, Shanghai Ocean

University,Chinamluo@shou.edu.cn

${ }^{2}$ Alfred-Wegener-Institute Helmholtz Center for Polar and Marine Research, Germany frank.wenzhoefer@awi.de

${ }^{3}$ University of Southern Denmark, Nordic Centre for Earth

Evolution,Denmarkrnglud@biology.sdu.dk

With the aim of understanding the composition and provenance of the sediments in the Atacama Trench region, major and minor elements as well as clay mineralogy were analyzed on a total of eight short cores collected from water depths ranging between 2,560 and $8,085 \mathrm{~m}$. Six cores recovered along the trench axis show generally constant downcore trends and limited differences among different cores in Al-normalized major element ratios. This results in relatively similar chemical index of alteration (CIA) of 55-60, suggesting moderately-altered sediments in the trench axis. The abyssal site (S7) also show constant Al-normalized major element ratios and moderate CIA values, but the continental slope site (S1) exhibits lower CIA values $(<50)$ indicative of less altered sediments compared to trench axis sites.

The only exceptions to this overall pattern were the ratios of $\mathrm{Mn} / \mathrm{Al}$ and $\mathrm{Fe} / \mathrm{Al}$. The $\mathrm{Mn} / \mathrm{Al}$ profiles of trench axis cores have well-developed peaks, which represent the depths of oxidation fronts. Notably, four among the six trench axis cores (S3, S4, S5, and S6) have double or triple Mn/Al peaks, which presumably reflect the downward migration of the oxidation fronts due to unstable sediment deposition within the trench. This inference is in agreement with the observations of ${ }^{14} \mathrm{C}$-TOC age reversals in these cores. In addition, XRD analysis of bulk sediments show that the sediments are mainly composed of quartz, plagioclase, clay minerals, and hornblende, and thus of terrigenous origin with little volcanogenic imprint. The clay mineral assemblages analysis reflects that all the sites are dominated by illite, followed by smectite, chlorite, and kaolinite. High illite contents are associated with abundant plutonic source rocks on the northern Chilean margin. Furthermore, the illite has very good crystallinity $\left(0.16-0.38 \Delta^{\circ} 2 \theta\right)$, pointing to low chemical weathering activity and arid climate in the source area that could be the Atacama desert. This study extends our knowledge of the sources and transport of sediments to the deepest sector of Earth's surface. 